\title{
FLASH DISSOLVING SUBLINGUAL ALMOTRIPTAN MALATE LYOTABS FOR MANAGEMENT OF MIGRAINE
}

\author{
ABEER AHMED KASSEM ${ }^{1,2 *}$, GIHAN SALAH LABIB ${ }^{2}$ \\ 1Department of Pharmaceutical Sciences, Faculty of Pharmacy, Princess Nourah bint Abdulrahman University, Riyadh, Saudi Arabia, \\ 2Department of Pharmaceutics, Faculty of Pharmacy, Alexandria University, Alexandria, Egypt
} Email: abeerkassem2002@gmail.com

Received: 01 Oct 2016 Revised and Accepted: 08 Nov 2016

\begin{abstract}
Objective: Development of sublingual fast dissolving lyophilized almotriptan tablets, to enhance its pre-gastric absorption and so alleviating the gastrointestinal dysmotility that is commonly associated with migraineurs.

Methods: Primary almotriptan lyophilized tablets (Alm-lyotab), were prepared using polyvinyl alcohol (PVA), polyvinyl pyrrolidone (PVP), gelatin, or sodium alginate, as a bulk forming agent and mannitol as a disintegrant, cryoprotectant and taste improver. Physical properties, wetting time, in vitro dissolution and disintegration behaviour, were investigated. A combination of PVP, gelatin and chitosan in different ratios with mannitol were developed and characterised for further improvement. Optimised formula was examined by scanning electron microscope (SEM), differential scanning calorimetry (DSC) and Fourier-transform infrared spectroscopy (FTIR)

Results: Both PVP and gelatin primary formulations showed elegant appearance with fast in vitro disintegration time of 5.67 and 5.64 sec, short wetting time of 4.06 and $4.05 \mathrm{sec}$, respectively, and high in vitro release rate of about $80 \%$ after 1 min, thus they were selected for further improvement. Optimised formula from polymer blend formulations (F8) which consisted of PVP: gelatin: chitosan in a ratio of its constituting solutions of 1:5:0.5, exhibited an elegant appearance, drug content of $98.75 \%$, in vivo disintegration time of 1.85 sec and complete drug release within $1 \mathrm{~min}$. SEM micrographs revealed spongy, highly porous structure. DSC results indicated the presence of the drug in its crystalline form. FTIR studies revealed no interaction between the drug and excipients.
\end{abstract}

Conclusion: Sublingual instantly dissolving Almo-lyotab was successfully developed and may constitute an advance in the management of acute migraine attacks.

Keywords: Almotriptan, Lyophilization, Sublingual, Fast-dissolving, Migraine

(C) 2017 The Authors. Published by Innovare Academic Sciences Pvt Ltd. This is an open access article under the CC BY license (http://creativecommons.org/licenses/by/4. 0/] DOI: http://dx.doi.org/10.22159/ijpps.2017v9i1.15489

\section{INTRODUCTION}

Migraine a headache is a neurovascular disorder often initiated by a trigger and characterised by a headache, which may be accompanied by a variety of multiple organ/system symptoms, such as nausea, allodynia, vomiting, and urinary frequency [1]. It may be associated with intense unilateral pain as well as photosensitivity and photosensitivity [2]. The emersion of migraine-specific, serotonin receptor agonists; triptans were a breakthrough in the management of a migraine. They are selective agonists of specific 5-hydroxytryptamine (5-HT) receptors: the $5-\mathrm{HT}_{1 \mathrm{~B}}$ and $5-\mathrm{HT}_{1 \mathrm{D}}$ receptors. Migraine relief by triptans results from vasoconstriction of pain-producing intracranial blood vessels and interruption of pain-signal transmission within the brainstem trigeminal nuclei [3]. Sumatriptan was the first synthesised triptan available for clinical use in the United States in 1992 [4]. Although it revolutionised the treatment of a migraine, it demonstrated some drawbacks, e. $g$. poor oral bioavailability, erratic absorption, high rate of headache recurrence and contraindication in patients with coronary artery disease [5]. Therefore, second generation triptans with higher oral bioavailability have been developed to improve the treatment of a migraine [4]. Almotriptan is a second generation highly selective 5$\mathrm{HT}_{1 \mathrm{~B} / 1 \mathrm{D}}$ agonist used to alleviate the migraine pain. For the relief of single attacks of a migraine, oral almotriptan $12.5 \mathrm{mg}$ had similar efficacy to oral sumatriptan $50 \mathrm{mg}$. In addition, patients given almotriptan reported less concern with adverse effects, with a lower incidence of chest pain Most adverse events are of mild or moderate intensity, e. g. dizziness, fatigue, headache, somnolence and skeletal pain [6].

Almotriptan is well-absorbed after oral administration, with an absolute bioavailability of about 70\% and elimination half-life of 3-4 h. After oral administration, maximal plasma concentrations are achieved between 1-3 h later [7]. In some animal species, oral bioavailability varies in the range of $18.7-79.6 \%$ depending on the degree of absorption and first-pass effect metabolism [8]. In humans, after a single subcutaneous dose its bioavailability is complete and time to maximum plasma concentration is about 5-15 min [9]. Almotriptan is commercially available as a conventional immediate release tablet ( 6.25 and $12.5 \mathrm{mg}$ ). As a substantial proportion of migraineurs suffer from nausea or vomiting during attacks, the oral treatment may be unsatisfactory. On the other hand, parenteral route lacks both self-administration and acceptance by most individuals. Hence, alternative routes for almotriptan administration were investigated; such as nasal [10,11], transdermal [12], vaginal [13] and pulmonary [14] routes. However, these investigations are scarce [15]. Sublingual route for the delivery of fast dissolving almotriptan tablets offers the combined advantages of convenience, patient compliance, ability of administration in the absence of water, prompt disintegration, dissolution, and pre-gastric absorption in the sublingual area and thus avoiding the hepatic first pass metabolism and alleviating the gastrointestinal (GI) dysmotility that usually associated with the migraine attack.

The present study aimed at preparing a promptly dissolving sublingual almotriptan malate sponge formulation "Alm-lyotab" using the lyophilization (freeze-drying) technique in order to mitigate the GI dysmotiliy, attain immediate release and thus ensure swift relief of migraine attack headache.

Technologies for preparing fast dissolving dosage forms include; lyophilization [16], spray drying [17], sublimation [18], addition of super-disintegrants $[19,20]$, and others $[21,22]$. The oral lyophilizates has been developed for large-scale production in recent years and many are approved for marketing. The Zydis (Catalent Pharma Solutions, Somerset, NJ) lyophilization technology provided the first approved orodispersible tablets (Claritin Reditabs, Schering-Plough, Kenilworth, NJ) in the United States in 1996 [23] 
Because of the high porosity, oral lyophilizates disintegrate or dissolve in oral cavity faster than other systems [16].

Freeze drying is the process in which solvent is sublimed from a frozen solution or suspension with a structure forming additive. This technique creates an amorphous porous structure that can dissolve instantly [21]. Typical oral lyophilizates consist of a drug enclosed in a water soluble matrix made of a hydrophilic structure-forming polymer (usually gelatin) and a bulking agent in order to improve the mechanical strength of the oral lyophilizates when handled (usually menthol). Other adjuvants may be sweetening agents, tastemasking additives and preservatives [24, 25].

The type and amount of the lyophilized tablet's components have a significant influence on their characteristics. In this study, many sublingual almotriptan malate lyophilized tablet formulations using different polymers has been developed and characterised. The optimised formula was subjected to further investigations. Based on our knowledge, oral almotriptan lyophilizate has not been previously demonstrated in literatures.

\section{MATERIALS AND METHODS}

\section{Materials}

Almotriptan malate was a kind gift from Amriya Pharmaceutical Industries, Alexandria, Egypt. Polyvinyl pyrrolidone (PVP K25) was purchased from Fluka AG (Buchs, Switzerland). Chitosan, $\mathrm{C}_{30}$, $85.87 \%$ degree of deacetylation, was purchased from Saniver Ltd, Hong Kong. High viscosity sodium alginate was purchased from Sisco Research Laboratories Pvt. Ltd., Mumbai, India. Polyvinyl alcohol (PVA), Mowiol ${ }^{\circledR}$ 40-88: E. I. du-Pont de Nemours Co., Wilmington, Delaware, USA. Gelatin was purchased from Adwic, ElNasr Pharmaceutical Chemicals Co., Egypt. Mannitol was purchased from Sigma-Aldrich Co, St Louis, MO, USA. All other chemicals were of the analytical or pharmaceutical grade.

\section{Preparation of Almotriptan malate lyotab (Alm-lyotab) by lyophilization}

Almotriptan malate lyotabs were prepared by freeze-drying technique [16]. The composition of different Alm-lyotab formulations is illustrated in tables 1 and 2. Each polymer was dissolved in the appropriate amount of purified water, except chitosan was dissolved in $0.25 \%$ acetic acid, in order to obtain the demonstrated concentrations. Mannitol solution $(1 \%)$ in purified water was added to all formulations. For single polymer formulations (F1-F4) (table 1), the polymer was dissolved in purified water, then an equal volume of mannitol solution (1\%) was added and mixed, using a magnetic stirrer (Bunsen, Spain). For other formulations (F5-F13) (table 2), polymeric solutions of PVP and chitosan, in the concentrations mentioned in the table, were mixed together in a volume ratio of $1: 1$. A mixture of gelatin $(5 \%)$ and mannitol (1\%) solutions in a volume ratio of $1: 1$ was prepared and added to each formulation, to constitute $50 \%$ of each lyotab volume, followed by continuous stirring using a magnetic stirrer. The concentration of excipients used was optimised during our study to obtain a strong and elegant lyotab that could be easily handled. The calculated weight of almotriptan malate was introduced into each formulation so as to contain $6.25 \mathrm{mg} /$ lyotab. The resultant gel was allowed to settle for removing air. Freeze-dried Alm-lyotabs were prepared as follows: the wells of PVC blisters ( $8 \mathrm{~mm}$ in diameter) were filled with $300 \mu \mathrm{l}$ of prepared formula, then the blisters were subjected to $-80^{\circ} \mathrm{C}$ for $24 \mathrm{~h}$, followed by freeze drying for further 24 h, on the pre-frozen shelves (Alpha 2-4, Christ, Osterode, Germany).

\section{Characterization of Almotriptan malate lyotabs}

\section{Visual characterization}

Freeze-dried Alm-lyotabs, were visually inspected concerning their shape, integrity and surface. Their adhesion to the blisters and the easiness of taking them out were also observed.

\section{Weight variation}

The test was applied to five Alm-lyotabs for each formulation (F5F13). Each Alm-lyotab was individually weighed using sensitive pharmaceutical balance and the mean weight of 5 and the standard deviation (in $\mathrm{mg}$ ) were calculated.

\section{Thickness}

The thickness of each Alm-lyotab (F5-F13) was measured at 10 points using a micrometre. The mean thickness of 6 and the standard deviation (in $\mathrm{mm}$ ) were calculated.

\section{Drug content}

Drug content was determined by dissolving one Alm-lyotab in $250 \mathrm{ml}$ distilled water under continuous shaking for $24 \mathrm{~h}$ in a thermostated shaking water bath (GFL Type 1083, Gesellschaft Fur Labortechnik, $\mathrm{GmbH}$ and Co., Burgwedel, West Germany) maintained at $37^{\circ} \mathrm{C}$ and left another day for equilibrium. The resulting solution was filtered through a millipore filter $0.45 \mu \mathrm{m}$ and the amount of almotriptan malate was then determined spectrophotometrically (UltravioletSpectrophotometer, Pharmacia LKB Ultrospec III double beam, England) at $\lambda \max 285 \mathrm{~nm}$, after appropriate dilution, according to the calibration curve constructed at the same wavelength. Each sample was analysed as triplicate. Placebo formulations were treated as previously mentioned and used as a reference.

\section{Wetting time}

Six circular tissue papers were placed in a Petri dish of $15 \mathrm{~cm}$ diameter. Water $(20 \mathrm{ml})$ containing $0.5 \%$ amaranth, a water-soluble dye, was added to the Petri dish. One Alm-lyotab was carefully placed on the surface of each of the tissue papers. The time required for the upper surface of the tablets to be coloured was noted as the wetting time. Wetting time was recorded using a stopwatch [26]. Mean values of six and standard deviation were calculated.

\section{Disintegration test}

\section{Modified disintegration test}

A Petri-dish (10 cm diameter) was filled with $10 \mathrm{ml}$ of distilled water. Each Alm-lyotab was carefully put in the centre of Petri-dish and the time for the tablet to completely disintegrate was noted [27]. All results are presented as mean value $(n=6)$.

\section{In vivo disintegration study}

For PVP/chitosan formulations (F5-F13), in vivo disintegration time was performed in six human volunteers after giving informed written consent. Prior to the test, all volunteers were asked to rinse their mouths with distilled water. One Alm-lyotab was placed under his/her tongue and immediately the time was recorded, then the in vivo disintegration time was reported, as immediately after the last noticeable mass had disintegrated. The subjects were asked to spit out the content of the oral cavity after tablet disintegration and rinse their mouths with distilled water. The swallowing of saliva was prohibited during the test, and also saliva was rinsed from the mouth after each measurement. The test results are presented as mean value \pm SD [28]

\section{In vitro dissolution study}

The dissolution study of Alm-lyotabs was carried out using the USP rotating paddle method in dissolution apparatus (Pharma Test Dissolution Tester, Germany) at $37 \pm 0.5^{\circ} \mathrm{C}$ and $50 \mathrm{rpm}$ using $250 \mathrm{ml}$ of phosphate buffer, pH 6.8 as dissolution medium. Samples $(5 \mathrm{ml})$ were withdrawn at predetermined time intervals $1,3,5,10,20,30$ and 45 min. filtered, then analysed spectrophotometrically at $285 \mathrm{~nm}$. The withdrawn volume was replenished with the fresh previously warmed medium. The dissolution test was performed in triplicates.

\section{Morphological studies}

The morphology of the selected Alm-lyotab formula was investigated, for both cross-section and surface characteristics, by scanning electron microscope (SEM) analysis. The sample was cut with a razor blade to expose the inner structure, fixed on a stub and coated with gold-palladium under an argon atmosphere using a gold sputter module in a high vacuum evaporator. Samples were then observed by SEM (JSM-5510, Joel Ltd, Tokyo, Japan) equipped with a digital camera. 


\section{Differential scanning calorimetry (DSC)}

DSC thermograms of selected formula, individual components and physical mixture were recorded using a differential scanning calorimeter (Perkin Elmer, Germany). About $5 \mathrm{mg}$ of sample was crimped in a standard aluminium pan and heated in a temperature range of $40{ }^{\circ} \mathrm{C}$ to $250^{\circ} \mathrm{C}$ at a heating rate of $10^{\circ} \mathrm{C}$ per minute in a nitrogen atmosphere.

\section{Fourier transform infra-red spectroscopy (FT-IR)}

The optimised formula was subjected to FT-IR spectroscopy in a Fourier-transform infrared spectrophotometer (Perkin Elmer, Germany) in the range of $4000-400 \mathrm{~cm}^{-1}$ as $\mathrm{KBr}$ pellets.

\section{Stability test}

The optimised formula was re-evaluated, concerning its appearance, drug content, in vitro drug release and disintegration behaviour after being stored at $25{ }^{\circ} \mathrm{C}$ and $40 \% \mathrm{RH}$ for $4 \mathrm{w}$.

\section{Statistical analysis}

Results were analysed by using the software SPSS 17.0 (SPSS Inc., Chicago, USA) applying one-way ANOVA test and Student t-test. Differences between formulations were considered to be significant at $\mathrm{p}<0.05$.

\section{RESULTS AND DISCUSSION}

Fast disintegrating oral formulations are designed to disintegrate and/or dissolve instantly upon contact with saliva without the need of water or chewing [23]. These formulations offer many advantages for almotriptan delivery, e.g. improved convenience, patient compliance, and pre-gastric absorption if applied buccally or sublingually and thus avoiding hepatic first pass metabolism and alleviating the gastrointestinal dysmotility that is usually associated with migraineurs [1]. Mouth fast dissolving films of almotriptan were previously prepared by solvent casing method, using HPMC E15, HPMC E4 and gelatin as the film forming agents, PEG 400 as a plasticizer, and sodium starch glycolate as disintegrant [29]. Fast disintegrating orodispersible almotriptan tablets were manufactured by direct compression using super-disintegrants: crospovidone, croscarmellose sodium, and sodium starch glycolate [30]. In another study, sodium starch glycolate, povidone K-30, mannitol and microcrystalline cellulose were used [31].

The lyophilization technique is an elegant technology. Owing to their high porosity, oral lyophilizates can promptly disintegrate or dissolve in the oral cavity [16]. In this study, many oral lyophilizate formulations of almotriptan malate lyotabs have been developed using either single structure-forming agent: PVA, PVP, gelatin, or sodium alginate (table 1) and some selected combinations with chitosan as demonstrated in Tables 2. Mannitol was added to all formulations, as it crystallises during freezing, thereby providing an elegant appearance and rigidity and ensuring that the product is robust to handle and transport. Because mannitol is readily soluble, it also has the function of improving texture, taste, and mouthfeel [23]. In addition, it is used as cryoprotectant prior to lyophilization to protect the formulation from freezing damage, due to ice formation, and to minimise the particle size growth during lyophilization [28, 32].

Table 1: Composition and preliminary evaluation of single polymer Alm-lyotab formulations

\begin{tabular}{|c|c|c|c|c|c|c|c|}
\hline \multirow[t]{2}{*}{$\begin{array}{l}\text { Formula } \\
\text { Code }\end{array}$} & \multicolumn{4}{|c|}{$\begin{array}{l}\text { Composition of solutions (\%) } \\
\text { subjected to freez-drying }\end{array}$} & \multirow{2}{*}{$\begin{array}{l}\text { Drug content/Alm- } \\
\text { lyotab, } \\
\%( \pm S D)\end{array}$} & \multirow{2}{*}{$\begin{array}{l}\text { Wetting } \\
\text { time, } \\
\text { sec }( \pm S D)\end{array}$} & \multirow{2}{*}{$\begin{array}{l}\text { In vitro disintegration } \\
\text { time, } \\
\text { sec }( \pm \text { SD) }\end{array}$} \\
\hline & PVA & PVP & Gelatin & Sodium alginate & & & \\
\hline \multirow[t]{2}{*}{ F1 } & 5 & - & - & - & 95.64 & 19.67 & 28.67 \\
\hline & & & & & \pm 3.73 & \pm 1.53 & \pm 2.08 \\
\hline \multirow[t]{2}{*}{$\mathrm{F} 2$} & - & 5 & - & - & 98 & 4.06 & 5.67 \\
\hline & & & & & \pm 4.25 & \pm 0.2 & \pm 0.58 \\
\hline \multirow[t]{2}{*}{ F3 } & & - & 5 & - & 99.69 & 4.05 & 5.64 \\
\hline & & & & & \pm 3.48 & \pm 0.67 & \pm 0.45 \\
\hline \multirow[t]{2}{*}{$\mathrm{F} 4$} & - & - & - & 5 & 96.37 & 50.62 & 57.37 \\
\hline & & & & & \pm 2.82 & \pm 1.32 & \pm 5 \\
\hline
\end{tabular}

Each Alm-lyotab formulation contains $6.25 \mathrm{mg}$ almotriptan malate, mannitol solution (1\%) added to each polymer solution in a volume ratio 1:1, For drug content, values represent the mean $\pm S D(n=3)$. For disintegration time and wetting time, values represent the mean $\pm S D(n=6)$

In the first step of this study, different formulations (F1-F4) have been prepared using different polymers (table 1). The resulting oral lyophilizates were of acceptable appearance and texture, except for PVA formulation which exhibited pronounced brittleness, due to its reported glassy character at room temperature [33]. Both PVP (F2) and gelatin (F3) primary formulations showed fast in vitro disintegration behaviour of 5.67 and $5.64 \mathrm{sec}$ and short wetting time of 4.06 and $4.05 \mathrm{sec}$, respectively. Therefore, they exhibited a comparable high in vitro release rate. About $80 \%$ of the drug was released after $1 \mathrm{~min}$ for both formulations (fig. 1). Whereas, PVA (F1) and sodium alginate (F4) formulations exhibited longer disintegration time of 28.67 and 57.37 and also longer wetting time of 19.67 and $50.62 \mathrm{sec}$, respectively. Consequently, their release behaviour was slower to a great extent (fig. 1). It was previously reported that the permeability of PVA films to water depends on the crystallinity of the polymer [34]. Progressive swelling of PVA particles may lead to considerable structural changes such as the mobility of macromolecular chains, macromolecular relaxation and changes of the porous structure (shape, size and pore distribution). The drug release may be greatly controlled by its diffusivity through the water-filled pores in the swollen gel layer [33]. On the other hand, the poor drug release rate from F4 lyotabs may be attributed to the high viscosity grade of the sodium alginate used.

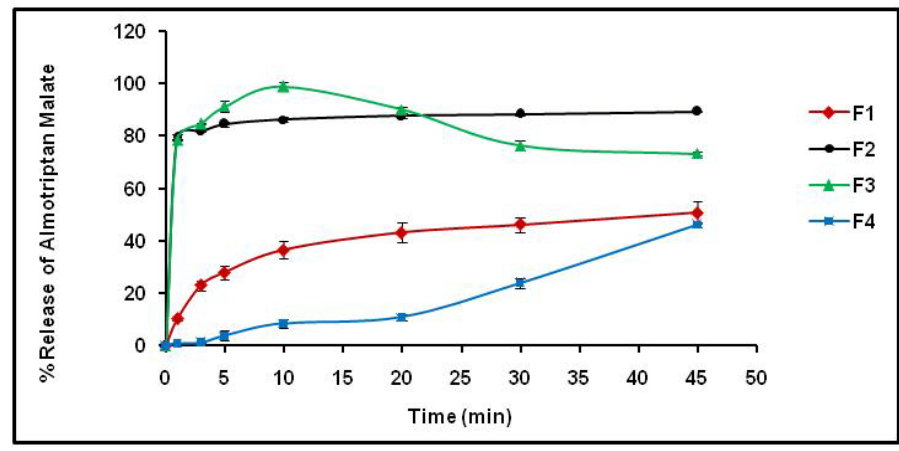

Fig. 1: Release profile of almotriptan malate from single polymer lyotab formulations. Each point represents the mean $\pm \operatorname{SD}(n=3)$ 
Both F1 and F4 were excluded, due to their relative slow disintegration, wetting times and release rates. On the other hand, F2 and F3 were subjected to further modifications for optimisation. A combination of PVP, gelatin and chitosan in different ratios were developed (table 2). Chitosan was added not only to improve the formulation behaviour, but also to impart mucoadhesion property and enhance drug absorption through the oral mucosa. Chitosan, as a mucoadhesive polymer may improve drug permeability by increasing its concentration in the close proximity to the epithelial surface, thereby increasing the concentration gradient across the epithelium. Alternatively or concomitantly, chitosan can act as a permeation enhancer by interfering with the intercellular lipidwater matrix and thereby alter the paracellular barrier properties of the epithelium $[35,36]$.

Table 2: Composition and evaluation of Alm-lyotab formulations with polymer mixture

\begin{tabular}{|c|c|c|c|c|c|c|c|c|c|}
\hline \multirow[t]{2}{*}{$\begin{array}{l}\text { Formula } \\
\text { Code }\end{array}$} & \multicolumn{2}{|c|}{$\begin{array}{l}\text { Composition of } \\
\text { solutions (\%) } \\
\text { subjected to } \\
\text { freez-drying }\end{array}$} & \multirow[t]{2}{*}{$\begin{array}{l}\text { Visual } \\
\text { characterization }\end{array}$} & \multirow[t]{2}{*}{$\begin{array}{l}\text { Thickness, } \\
\text { mm } \\
\text { (mean } \pm S D \text { ) }\end{array}$} & \multirow[t]{2}{*}{$\begin{array}{l}\text { Weight/Alm } \\
\text {-lytab, mg } \\
\text { (mean } \pm S D)\end{array}$} & \multirow[t]{2}{*}{$\begin{array}{l}\text { Drug } \\
\text { content/Alm } \\
\text {-lytab, } \\
\%( \pm S D)\end{array}$} & \multirow[t]{2}{*}{$\begin{array}{l}\text { In vitro } \\
\text { Disintegrati- } \\
\text { on time, } \\
\text { sec }( \pm S D)\end{array}$} & \multirow[t]{2}{*}{$\begin{array}{l}\text { In vivo } \\
\text { Disintegrati- } \\
\text { on time, } \\
\text { sec }( \pm S D)\end{array}$} & \multirow{2}{*}{$\begin{array}{l}\text { Time } \\
\text { for } \\
100 \% \\
\text { drug } \\
\text { release } \\
\text {, min }\end{array}$} \\
\hline & PVP & Chitosan & & & & & & & \\
\hline \multirow[t]{2}{*}{ F5 } & 1 & 0.25 & Rough & 2.62 & 17.80 & 99.55 & 2.54 & 2.44 & 30 \\
\hline & & & $\begin{array}{l}\text { surface/minimum } \\
\text { air bubbles }\end{array}$ & \pm 0.03 & \pm 0.66 & \pm 0.26 & \pm 0.05 & \pm 0.03 & \\
\hline \multirow[t]{2}{*}{ F6 } & 3 & 0.25 & Rough & 2.87 & 21.00 & 101.42 & 4.78 & 4.27 & 10 \\
\hline & & & $\begin{array}{l}\text { surface/minimum } \\
\text { air bubbles }\end{array}$ & \pm 0.02 & \pm 0.36 & \pm 3.50 & \pm 0.09 & \pm 0.38 & \\
\hline \multirow[t]{2}{*}{ F7 } & 5 & 0.25 & Smooth well formed & 3.41 & 25.20 & 99.6 & 4.05 & 4.05 & 3 \\
\hline & & & lyotab & \pm 0.04 & \pm 1.14 & \pm 4.278 & \pm 0.19 & \pm 0.06 & \\
\hline \multirow[t]{2}{*}{ F8 } & 1 & 0.5 & Smooth well formed & 2.66 & 15.43 & 98.75 & 4.78 & 1.85 & 1 \\
\hline & & & lyotab & \pm 0.02 & \pm 0.21 & \pm 1.96 & \pm 0.09 & \pm 0.14 & \\
\hline \multirow[t]{2}{*}{ F9 } & 3 & 0.5 & Rough & 2.84 & 19.67 & 99.26 & 8.95 & 1.98 & 3 \\
\hline & & & $\begin{array}{l}\text { surface/minimum } \\
\text { air bubbles }\end{array}$ & \pm 0.04 & \pm 1.34 & \pm 2.21 & \pm 0.14 & \pm 0.11 & \\
\hline \multirow[t]{2}{*}{ F10 } & 5 & 0.5 & Rough & 2.98 & 22.87 & 98.98 & 9.21 & 2.22 & 5 \\
\hline & & & $\begin{array}{l}\text { surface/more air } \\
\text { bubbles }\end{array}$ & \pm 0.01 & \pm 1.34 & \pm 2.04 & \pm 0.09 & \pm 0.1 & \\
\hline \multirow[t]{2}{*}{ F11 } & 1 & 0.75 & Rough & 2.50 & 19.20 & 99.94 & 11.64 & 3.6 & 1 \\
\hline & & & $\begin{array}{l}\text { surface/minimum } \\
\text { air bubbles }\end{array}$ & \pm 0.03 & \pm 0.53 & \pm 1.35 & \pm 0.17 & \pm 0.06 & \\
\hline \multirow[t]{2}{*}{ F12 } & 3 & 0.75 & Rough & 1.37 & 19.80 & 98.87 & 12.84 & 3.78 & 5 \\
\hline & & & $\begin{array}{l}\text { surface/minimum } \\
\text { air bubbles }\end{array}$ & \pm 0.03 & \pm 0.10 & \pm 2.15 & \pm 0.13 & \pm 0.09 & \\
\hline \multirow[t]{2}{*}{ F13 } & 5 & 0.75 & Rough & 1.27 & 19.80 & 99.43 & 14.07 & 3.99 & 20 \\
\hline & & & $\begin{array}{l}\text { surface/more air } \\
\text { bubbles }\end{array}$ & \pm 0.02 & \pm 0.10 & \pm 1.89 & \pm 0.07 & \pm 0.1 & \\
\hline
\end{tabular}

Each Alm-lyotab formulation contains $6.25 \mathrm{mg}$ almotriptan malate, 1:1 v/v ratio of mannitol (1\%) and gelatin (5\%) solution was added to each polymer solution in a volume ratio 1:1. For lyotab thickness, in vitro and in vivo disintegration time, values represent the mean \pm SD $(n=6)$. For weight variation, values represent the mean $\pm S D(n=5)$. For drug content, values represent the mean $\pm S D(n=3)$

Concerning the characteristics of these Alm-lyotab formulations (table 2), the diameter for all formulations was $7.8 \mathrm{~mm}$, their thickness ranged from 1.27-3.41 mm, average weight of 15.43-25.2 $\mathrm{mg}$ \% drug content from $98.87-101.42 \%$. An elegant appearance with smooth surface well-formed lyotabs was observed in both F7 and F8 formulations. Other formulations exhibited rough surface, with some air bubbles. Clear variation in both in-vitro and in vivo disintegration time values was recognised. Although the European Pharmacopoeia describes orodispersible tablets as tablets which should disintegrate within 3 min, many critics find that a maximum disintegration time of 3 min for any tablet is too long and that the presence of a gritty tablet in the patient's mouth for 3 min would be unpleasant and uncomfortable. According to the literature, the oral disintegration time of mouth-dissolved tablets is one minute or less, preferably about $30 \mathrm{~s}$ or less [37]. Also because Almo-lyotab was designed to be mainly absorbed in the sublingual area to be readily absorbed and exert its action promptly and also to bypass the gastrointestinal tract (GIT), it is necessary that the lyotab disintegrates within few seconds and rapidly dissolve so that most of the drug absorption takes place in the sublingual area before being swallowed. Upon illustration of the in vitro disintegration time of these formulations, we can observe that all formulations exhibited a very short disintegration time, ranged from $2.5-14 \mathrm{sec}$. The presence of the water-soluble polymer PVP in all formulations resulted in encouraging water pull inside the lyotabs with subsequent rapid disintegration and expected fast release rate. In one study, increasing the concentration of the PVP-k30 in oral lyophilizates of diclofenac sodium, resulted in negative effect. Although these formulations had fast disintegration time (less than 12 seconds), the formulas acquired incorrect appearance and multiple broken units [16]. Formulations containing $0.25 \%$ chitosan (F5-F7), showed a short in vitro disintegration time, ranged from $2.5-4.78 \mathrm{sec}$, whereas, those containing $0.5 \%$ chitosan (F8-F10), showed longer in vitro disintegration time, ranged from 4.78-9.21 sec. Increasing the chitosan concentration to $0.75 \%$ (F11-F13), led to a significant increase in in vitro disintegration time $(11.64-14 \mathrm{sec})$. It is considered that chitosan might swell and form a gel owing to penetration of the dissolution medium. But upon increasing chitosan concentration to $0.75 \%$, the gel structure became more stable and cohesive. Thus it may hinder more penetration of the dissolution medium which is necessary for further disintegration. It is worthy to note that, during lyotabs preparation, trying concentrations more than $0.75 \%$ of chitosan could not be applied due to the observed high viscosity of the formulation and difficulty of pouring into blisters.

Concerning the release rate of these formulations (fig. 2), it could be observed that all formulations possessed a high release rate. However, the formula of choice among all formulations was that containing $1 \%$ PVP, $5 \%$ gelatin, $0.5 \%$ chitosan, and $1 \%$ mannitol (F8), as it exhibited the best characteristics for the evaluated lyotabs. It showed an elegant appearance, smooth surface, with no air bubbles included, prompt disintegration with in vitro and in vivo disintegration time of 4.78 and $1.85 \mathrm{sec}$, respectively. Moreover, the instant drug release was obtained; after only one minute, the whole 
drug in the lyotab was completely released into the release medium. The fast disintegration of lyotabs and instant drug release in the mouth might lead to promote absorption through the oral mucosa. This is a very important point since the aim of this work was to prepare formulations capable of exhibiting rapid systemic distribution through the sublingual mucosa bypassing the GIT.

The SEM micrographs obtained for such an optimised Alm-lyotab formulation (fig. 3), explained this swift drug release. It can be observed that the formulation acquired a sponge-like, highly porous structure upon lyophilization, potentially providing an ideal path for water ingress and subsequent prompt rehydration and dissolution of the formula. The previous study also explained the prompt disintegration and dissolution of nimesulide lyophilized orally disintegrating tablets, by the rapid penetration of water, due to the highly porous nature of the tablets as observed in the obtained scanning electron micrographs [28].

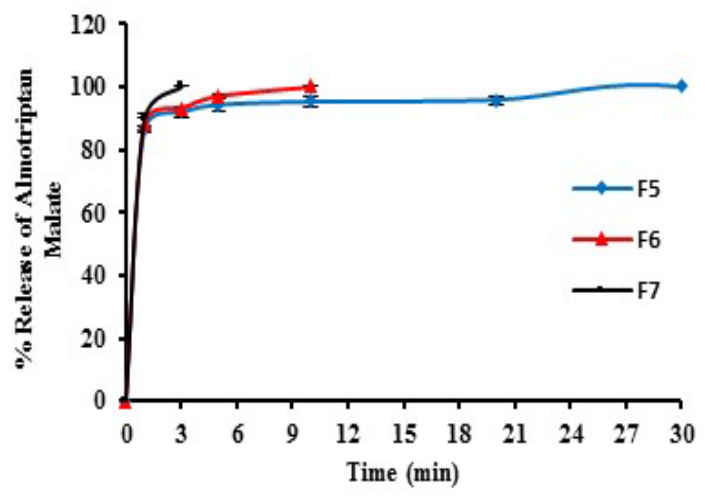

a

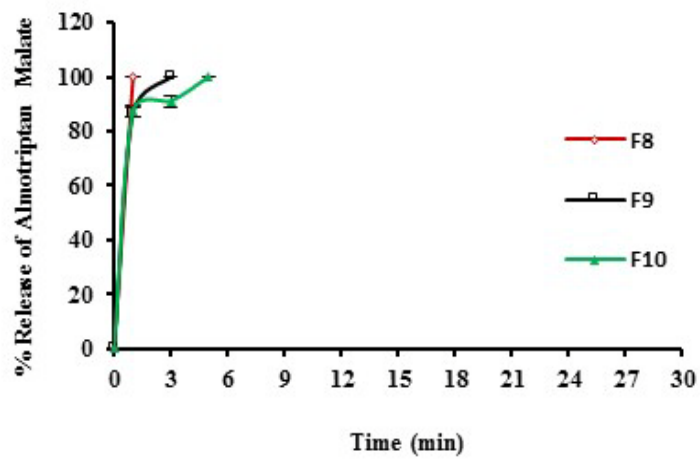

b

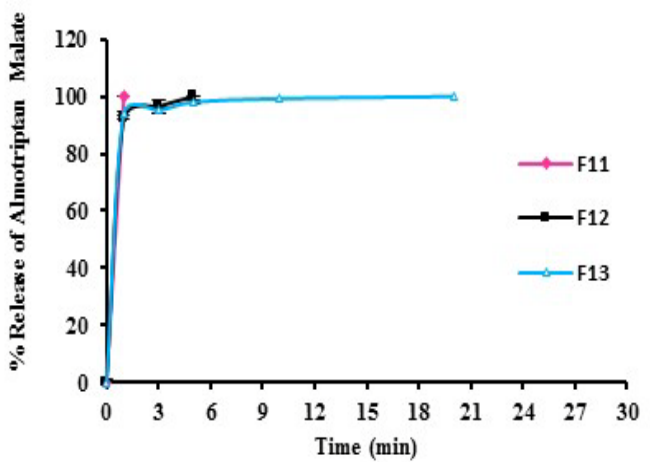

c

Fig. 2: Release profile of almotriptan malate from lyotab formulations, a) F5-F7, b) F8-F10, c) F11-F13. Each point represents the mean $\pm S D(n=3)$
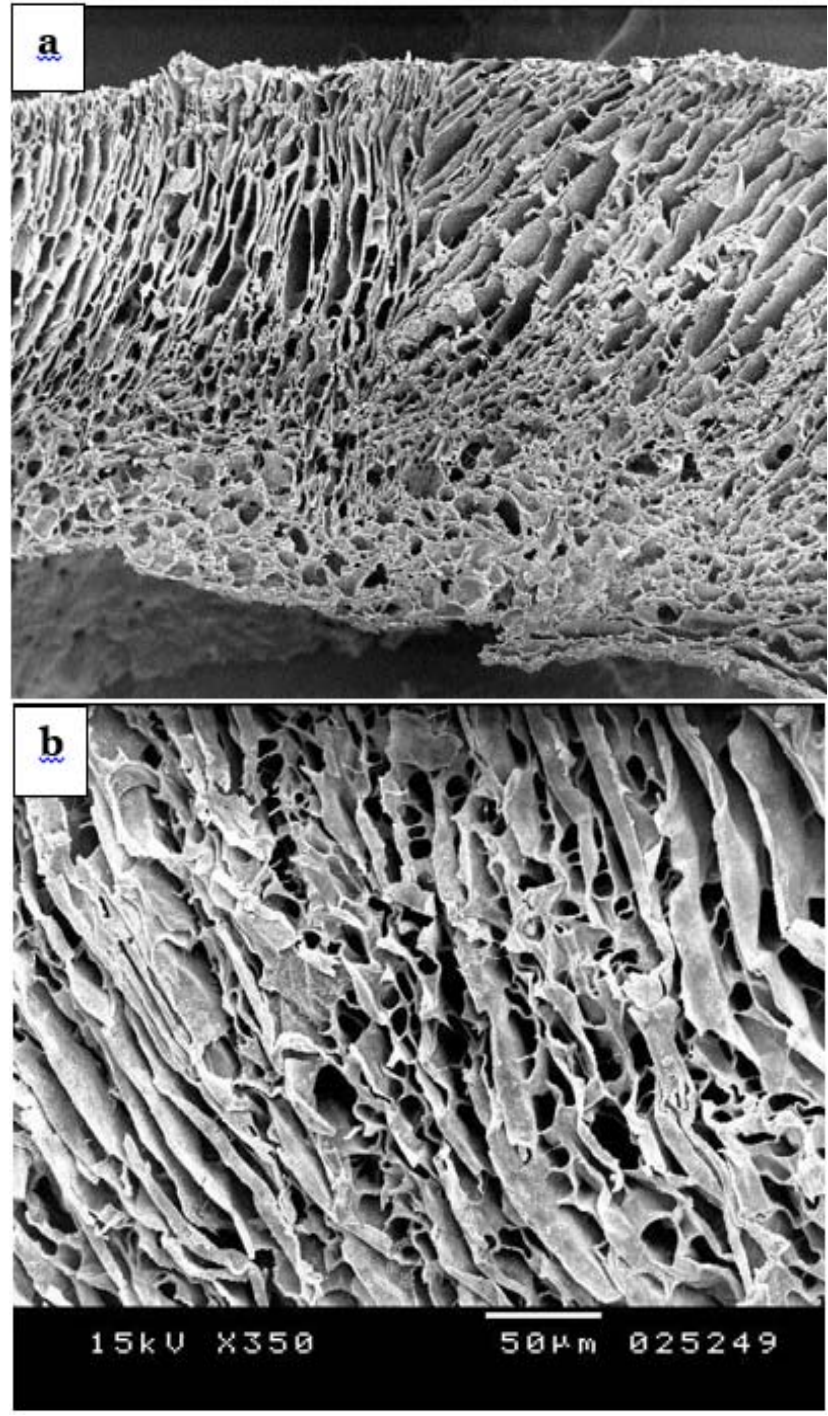

Fig. 3: Scanning electron micrographs of F8 Alm-lyotab formulation in cross-section view (a) and surface view (b)

\section{FTIR and DSC results}

The IR spectrum of almotriptan shows fundamental peaks correspond to the major functional groups in the structure [29]. The peak at $3373 \mathrm{~cm}^{-1}$ refers to the $\mathrm{N}-\mathrm{H}$ stretching of secondary amine and that at $2929 \mathrm{~cm}^{-1}$ is due to C-H stretching. Other significant peaks are that of aromatic $\mathrm{C}=\mathrm{C}$ at $1651 \mathrm{~cm}^{-1}, \mathrm{C}-\mathrm{N}$ at $1202 \mathrm{~cm}^{-1}$, and the peak at $1155 \mathrm{~cm}^{-1}$ corresponds to sulfone.

Comparing the IR spectrum of pure almotriptan and the spectra of physical mixture and the drug formulation, we found that the fundamental peaks are still detectable as shown in fig. 4 with the $\mathrm{N}$ $\mathrm{H}$ stretching appears broader due to the presence of hydroxyl groups in the additives. This indicates no interference between the drug and excipients in the formulation.

Fig. 5 a shows the DSC thermogram of pure almotriptan malate showing one main prominent sharp characteristic endothermic peak at $166.3{ }^{\circ} \mathrm{C}$ due to the melting transition point of almotriptan [11].

No characteristic peak was observed at $166.3{ }^{\circ} \mathrm{C}$, in the case of Alm-lyotab (F8), suggesting that almotriptan is molecularly dispersed in the matrix in an amorphous form produced by the process of lyophilization. The thermogram of the physical mixture showed a small endotherm corresponding to the melting point of the drug. 


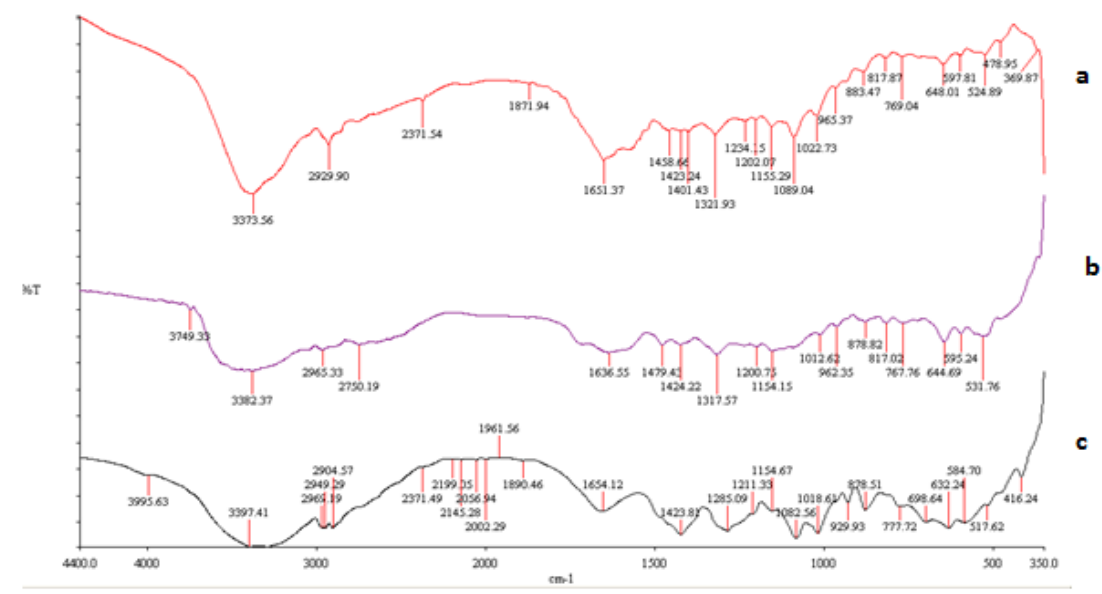

Fig. 4: FTIR spectra for a) Pure almotriptan malate, b) Formula F8, and c) Formula F8 physical mixture

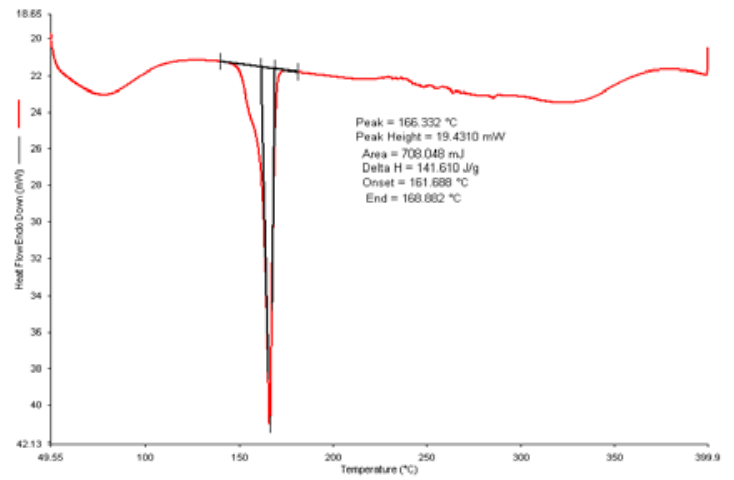

a

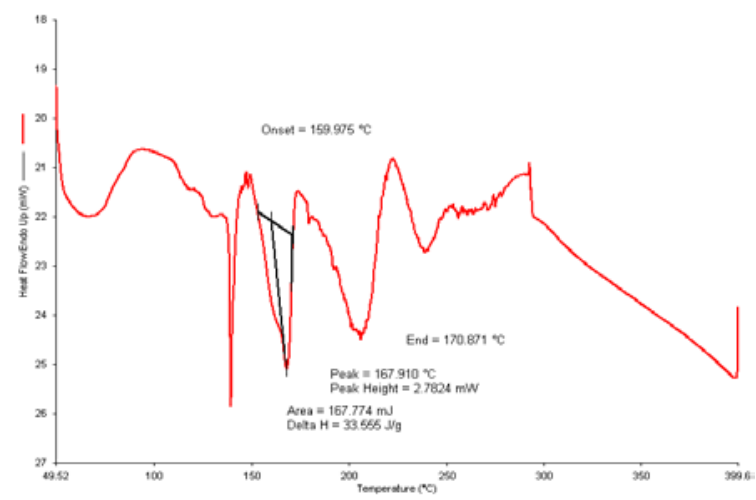

b

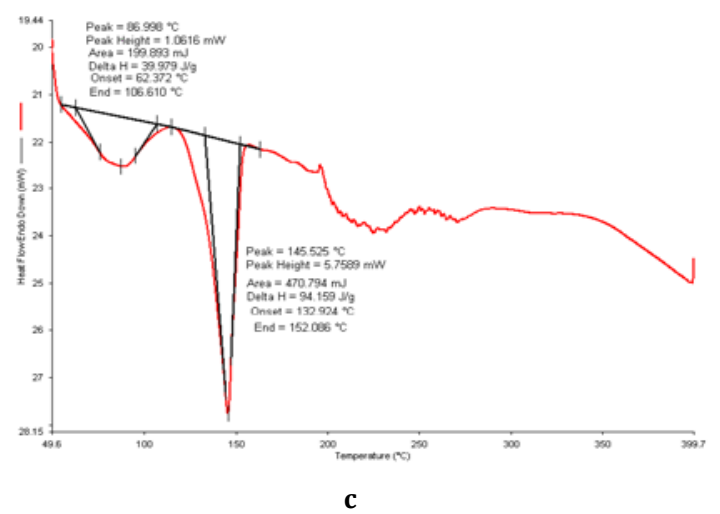

Fig. 5: DSC thermograms of a) Pure almotriptan malate, b) Formula F8 physical mixture, and c) Formula F8

\section{Stability}

The rationale for carrying on stability studies is that the lyophilized tablets show significant porosity, and one can expect that they can absorb moisture very easily and become deformed upon storage. No changes in Alm-lyotab (F8) weight, or shape after $4 \mathrm{w}$ storage at $40 \% \mathrm{RH}$ was observed. In addition, no significant change $(\mathrm{p}<0.5)$ in disintegration time, drug content or drug release profile was detected, compared to as before storage. Comparable results were observed with lyophilized orally disintegrating tablets containing nimesulide, with two formulations (G4 and G13). Both formulations constituted 5\% drug, 2\% gelatin, $0.886 \%$ mannitol and glycine, but for formula G13, 1\% PVP K90 was added, to enhance its initial dissolution rate [28]

\section{CONCLUSION}

We demonstrated that an instantly dissolving sublingual Almolyotab (F8) is a promising formulation, prepared easily by lyophilization technique, utilising safe polymers resulting in swift in vivo disintegration time within $1.85 \mathrm{sec}$, and complete drug release within only one minute. These results suggest that F8 formulation would be an alternative to conventional almotriptan oral formulations, owing to instant absorption in the sublingual area, reflected as rapid relief of a migraine headache, bypassing the GIT pathway and hence mitigating the GIT dysmotility and hepatic firstpass metabolism which might be caused after oral administration.

\section{CONFLICTS OF INTERESTS}

Authors have none to declare

\section{ACKNOWLEDGMENT}

Authors would like to thank Dr. Nashwah Gadallah Mohamed, Associate Professor of pharmaceutical chemistry, in faculty of pharmacy, Princess Nourah bint Abdulrahman University, for her contribution to the analysis of FTIR results.

\section{REFERENCES}

1. Chu J. Goldfrank's toxicologic emergencies. In: Nelson LS, Lewin NA, Howland MA, Hoffman RS, Goldfrank LR, Flomenbaum NE. editors. McGraw-Hill Medical New York; 2010. p. 763-9.

2. Ali AM, Awad TG, Al-Adl NM. Efficacy of combined topiramate/thioctic acid therapy in migraine prophylaxis. Saudi Pharm J 2010;18:239-43.

3. Minor DS, Jackson D. Pharmacotherapy in primary care. In: Linn WD. Wofford MR, O'keefe M, Posey L. editors. McGraw Hill: New York; 2009. p. 219-32.

4. Sanders-Bush E, Hazelwood L. Goodman and Gilman's the pharmacological basis of therapeutics. In: Brunton LL, Chabner BA, Knollmann BC. editors. McGraw-Hill Medical New York; 2011. p. 381-417.

5. Saxena PR, Ferrari MD. Monthly update: central and peripheral nervous systems: pharmacology of antimigraine 5-HT1D receptor agonists. Expert Opin Invest Drugs 1996;5:581-93. 
6. Keam S, Goa K, Figgitt D. Almotriptan: a review of its use in a migraine. Headache: J Head Face Pain 2003;43:300-1.

7. Gras J, Llenas J, Jansat JM, Jáuregui J, Cabarrocas X, Palacios JM. Almotriptan, a new anti-migraine agent: a review. CNS Drug Rev 2002;8:217-34.

8. Aubets J, Cardenas A, Salva M, Jansat J, Martinez-Tobed A, Palacios J. Disposition and metabolism of almotriptan in rats, dogs and monkeys. Xenobiotica 2006;36:807-23.

9. Jansat JM, Costa J, Salvà P, Fernandez FJ, Martinez-Tobed A Absolute bioavailability, pharmacokinetics, and urinary excretion of the novel antimigraine agent almotriptan in healthy male volunteers. J Clin Pharmacol 2002;42:1303-10.

10. Pradhan V, Gaikwad R, Samad A, Prabhakar B. Formulation and evaluation of almotriptan malate nasal drops. Indian J Pharm Sci 2009;71:727-9.

11. Abbas Z, Marihal S. Gellan gum-based mucoadhesive microspheres of almotriptan for nasal administration: formulation optimisation using factorial design, characterization, and in vitro evaluation. J Pharm Bioallied Sci 2014;6:267-77.

12. Calatayud-Pascual M, Balaguer-Fernandez C, Serna-Jimenez C, Del Rio-Sancho S, Femenia-Font A, Merino V, et al. Effect of iontophoresis on in vitro transdermal absorption of almotriptan. Int J Pharm 2011;416:189-94.

13. Pauletti GM, Wilson M, Soderstrom R, Kishorkumar DJ, Ritschel WA. Coated vaginal device for delivery of anti-migraine and anti-nausea drugs; 2010.

14. Main MJ, Pulmonary formulations of triptans; 2011.

15. Kassem A. Formulation approaches of triptans for the management of a migraine. Curr Drug Delivery 2016;13:882-98.

16. Safarab R, Abdelwahed W, Chehna MF, Degobert G, Fessi H. Preparation and characterization of new oral lyophilizates containing a non-steroidal anti-inflammatory drug. Int J Pharm Pharm Sci 2011;3:108-14.

17. Mishra DN, Bindal M, Singh SK, Vijaya Kumar SG. Spray dried excipient base: a novel technique for the formulation of orally disintegrating tablets. Chem Pharm Bull 2006;54:99-102.

18. Narmada G, Mohini K, Prakash Rao B, Gowrinath D, Kumar K Formulation, evaluation and optimisation of fast dissolving tablets containing amlodipine besylate by a sublimation method. Ars Pharm 2009;50:129-44.

19. Sharma S, Gupta G. Formulation and characterization of a fastdissolving tablet of promethazine theoclate. Asian J Pharm 2014;2:70-2.

20. Singh SK, Mishra DN, Jassal R, Soni P. Fast disintegrating combination tablets of omeprazole and domperidone. Asian J Pharm Clin Res 2009;2:74-82.

21. Amipara LV. A review on fast dissolving tablet technology. J Biomed Pharm Res 2013;2:8-18.

22. Dey P, Ghosh A. Wafers: an innovative advancement of orodispersible films. Int J Appl Pharm 2016;8:1-7.
23. McLaughlin R, Banbury S, Crowley K. Orally disintegrating tablets: the effect of recent FDA guidance on ODT technologies and applications. Pharm Technol 2009;Suppl 2:1-7.

24. Swarbrick J. Encyclopedia of pharmaceutical technology. Informa Healthcare USA. Inc., New York. Informa Healthcare USA; 2007.

25. Luppi B, Bigucci F, Abruzzo A, Corace G, Cerchiara T, Zecchi V. Freeze-dried chitosan/pectin nasal inserts for antipsychotic drug delivery. Eur J Pharm Biopharm 2010;75:381-7.

26. Labib GS. Novel levocetirizine $\mathrm{HCl}$ tablets with enhanced palatability: synergistic effect of combining taste modifiers and effervescence technique. Drug Des Dev Ther 2015;9:5135-46.

27. Siddiqui $M N$, Garg G, Sharma PK. Fast dissolving tablets preparation, characterization and evaluation: an overview. Int ] Pharm Sci Rev Res 2010;4:87-96.

28. Shoukri RA, Ahmed IS, Shamma RN. In vitro and in vivo evaluation of nimesulide lyophilized orally disintegrating tablets. Eur J Pharm Biopharm 2009;73:162-71.

29. Talele Swati G, Harak Yogesh, Bakliwal Akshada A, N CG Formulation and evaluation of mouth dissolving film of almotriptan malate. J Pharm BioSci 2015;3:42-52.

30. Alladi A, Damodharan N. Formulation, taste masking and evaluation of almotriptan oral disintegrating tablets. Int J Pharm Sci Res 2012;3:3940-6.

31. Gowtham G, Reddy GR, Sathyanarayana R, Pandey V. Formulation and evaluation of almotriptan tablets. Res J Pharm Technol 2011;4:533-6

32. Fonte P, Reis S, Sarmento B. Facts and evidences on the lyophilization of polymeric nanoparticles for drug delivery. J Control Rel 2016;225:75-86.

33. Korsmeyer RW, Gurny R, Doelker E, Buri P, Peppas NA Mechanisms of solute release from porous hydrophilic polymers. Int J Pharm 1983;15:25-35.

34. Thombre AGaC JR. Biopolymers for controlled drug delivery. Encyclopedia of Pharmaceutical Technology. ed. Swarbrick JaB JC. Vol. 2. New York: Marcel Dekker, Inc; 1990.

35. Nicolazzo JA, Reed BL, Finnin BC. Buccal penetration enhancers-how do they really work? J Control Rel 2005;105:1-15

36. Şenel S, Hincal AA. Drug permeation enhancement via buccal route: possibilities and limitations. J Control Rel 2001; 72:133-44.

37. Kuno Y, Kojima M, Ando S, Nakagami H. Evaluation of rapidly disintegrating tablets manufactured by phase transition of sugar alcohols. J Control Rel 2005;105:16-22.

\section{How to cite this article}

- $\quad$ Abeer Ahmed Kassem, Gihan Salah Labib. Flash dissolving sublingual almotriptan malate lyotabs for the management of a migraine. Int J Pharm Pharm Sci 2017;9(1):125-131. 